\title{
Understanding the Psychological, Physiological, and Genetic Factors Affecting Precision Pain Medicine: A Narrative Review
}

\section{Andrea Chadwick \\ Andrew Frazier \\ Talal W Khan \\ Erin Young}

Department of Anesthesiology, University of Kansas Medical Center, Kansas City, KS, USA
Correspondence: Andrea Chadwick 390 I Rainbow Blvd., Mail Stop 1034, Kansas City, KS, 66160, USA

Tel + I 9/3-588-6670

$\mathrm{Fax}+1913-588-3365$

Email anicol@kumc.edu
Purpose: Precision pain medicine focuses on employing methods to assess each patient individually, identify their risk profile for disproportionate pain and/or the development of chronic pain, and optimize therapeutic strategies to target specific pathological processes underlying chronic pain. This review aims to provide a concise summary of the current body of knowledge regarding psychological, physiological, and genetic determinants of chronic pain related to precision pain medicine.

Methods: Following the Scale for the Assessment of Narrative Review Articles (SANRA) criteria, we employed PubMed/Medline to identify relevant articles using primary database search terms to query articles such as: precision medicine, non-modifiable factors, pain, anesthesiology, quantitative sensory testing, genetics, pain medicine, and psychological.

Results: Precision pain medicine provides an opportunity to identify populations at risk, develop personalized treatment strategies, and reduce side effects and cost through elimination of ineffective treatment strategies. As in other complex chronic health conditions, there are two broad categories that contribute to chronic pain risk: modifiable and non-modifiable patient factors. This review focuses on three primary determinants of health, representing both modifiable and non-modifiable factors, that may contribute to a patient's profile for risk of developing pain and most effective management strategies: psychological, physiological, and genetic factors.

Conclusion: Consideration of these three domains is already being integrated into patient care in other specialties, but by understanding the role they play in development and maintenance of chronic pain, we can begin to implement both precision and personalized treatment regimens.

Keywords: pharmacogenetics, pharmacogenomics, phenotyping, neuroimaging, chronic pain, precision medicine, pain medicine

\section{Introduction}

The overarching definition of precision pain medicine is that diagnosis and treatment can be customized to an individual's specific risk profile. ${ }^{1,2}$ At its most basic, the ideology is based on using all available patient-level data to target therapies for that individual with regard to prediction, prevention, diagnosis, and treatment of disease, with the aim of improving symptoms and quality of life. By incorporating a given patient's individual profile of biological (molecular disease pathway(s), genetic, proteomic, metabolomic), psychological, and environmental context variables along with comorbid conditions, personal/cultural preferences, and other 
characterizing data, we should be able to improve efficacy and lessen treatment side effects while decreasing resource waste and improving cost effectiveness. ${ }^{1}$

In 2015, the United States launched the Precision Medicine Initiative which committed to fund and support research in the area of precision medicine in order to improve patient care and treatment outcomes. ${ }^{3}$ There is considerable overlap, yet subtle differences, between the terms "precision medicine" and "personalized medicine" and historically these terms have been used interchangeably. Personalized medicine is an older term, defined as individualized care that is customized for individual patients based on their characteristics, which may include genetics, disease biomarkers, treatment history, and other factors, but typically is based on a specific patient's symptoms. ${ }^{4}$ The goal of precision medicine is to maximize the accuracy by which patients are treated with existing treatment regimens and is informed through an understanding of the interrelation of an individual's profile of characteristics, including genetics, environment, and lifestyle, with specific inclusion of phenotypes and biological markers. These two approaches both explicitly depend on evidence-based medicine by incorporating problemsolving, application of research findings, clinical expertise, and patient preferences, values, and perspectives into the healthcare decision-making process.

However, in line with a report from the National Research Council in $2011,{ }^{5}$ we prefer to use the term precision pain medicine as it incorporates stratifying individuals into subgroups using a broader spectrum of patient characteristics (psychological, physiological, and genetic/ molecular). This then allows clinicians to recommend treatments with the greatest probability of effectiveness based on these stratifications. Eventually, this approach may lead to development of new therapeutic strategies that can be tailored to the biological mechanisms at work in a specific patient, thus crossing over into personalized pain management; however, there is still more work to be done.

We will focus the present review of precision pain medicine on psychological, physiological, and genetic factors, each of which represents multiple contributing subcategories. The relative contribution of each of these factor determinants will vary between patients, but it is their cumulative impact that increases or decreases a patient's risk for developing chronic pain and shapes the response to standard treatment strategies. The goal of this review is to provide a concise summary of the current body of knowledge regarding the three determinants of chronic pain related to precision pain medicine. By understanding all three domains and the role they play in the development and maintenance of chronic pain, we can begin to develop and implement both precise and personalized treatment regimens.

\section{Methodology}

The Scale for the Assessment of Narrative Review Articles (SANRA) criteria guided this review. ${ }^{6}$ We employed PubMed/Medline to identify relevant articles using the primary database search terms (used in combinations as illustrated in Table 1 to query PubMed indexed articles): precision medicine, non-modifiable factors, pain, anesthesiology, quantitative sensory testing, genetics, pain medicine, psychological, pharmacogenetics/pharmacogenomics, biomarker, and next-generation sequencing. After reviewing the literature, we narrowed our focus to two broad categories

Table I Search Terms and Results of PubMed/Medline Search for Articles Published from 1990 to 2021

\begin{tabular}{|l|c|}
\hline Combination Search Terms & $\begin{array}{c}\text { Number of Articles } \\
\text { Identified }\end{array}$ \\
\hline Precision medicine and genetics & 23,097 \\
Precision medicine and genomics & 14,648 \\
Pain medicine and genetics & 58,807 \\
Pain medicine and genomics & 12,128 \\
Precision medicine and pain & 1,557 \\
Anesthesiology and precision medicine & 1,014 \\
Anesthesiology and psychological & 3,343 \\
Pain medicine and psychological & 17,849 \\
Quantitative sensory testing and & 297 \\
psychological & 7 \\
Precision medicine and non-modifiable & \\
factors & 50 \\
Non-modifiable factors and pain & 0 \\
Precision medicine and non-modifiable & 18 \\
factors and pain & 1,538 \\
Precision pain medicine and quantitative & 445 \\
sensory testing & \\
Precision medicine and pain and & 1,854 \\
biomarker & \\
Anesthesiology and pain and biomarker & \\
Pain medicine and pharmacogenetics & \\
Pain medicine and pharmacogenomics & \\
Pain medicine and next generation & \\
sequencing & \\
Precision medicine and next generation & \\
sequencing & \\
\hline
\end{tabular}

Notes: Restricted search to 1990-2021. Search date: 7/21/2021. 
of health determining factors that should be considered in any patient profile of risk, those that are modifiable (eg, those that can be changed; psychological function, physiological/ sensory function, lifestyle factors) and those that are nonmodifiable (eg, those that cannot be changed; age, sex, race, genetics) (Figure 1). Of these, we have identified three exemplar determinants of health representing both modifiable and non-modifiable factors based on their potential contribution to patients' risk profiles for developing chronic pain and/or their response to pain management strategies. While these examples are not intended to be exhaustive of all variables relevant to a patient profile of risk, a growing body of evidence supports their novel relevance to the practice of precision pain medicine.

\section{Psychological Factors}

Psychological factors of pain encompass an expansive category of factors including mood, maladaptive pain coping styles such as pain catastrophizing, poor self-efficacy, kinesiophobia, injustice, and sleep-related impairments. These psychological constructs can be assessed using comprehensive pain phenotyping, which allows the categorization of patients based on a set of characteristics (both subjective and objective) in order to predict risk for developing chronic pain and treatment response. Phenotyping is typically performed by assessing these psychological factors and maladaptive coping styles using a variety of validated patient-reported questionnaires.

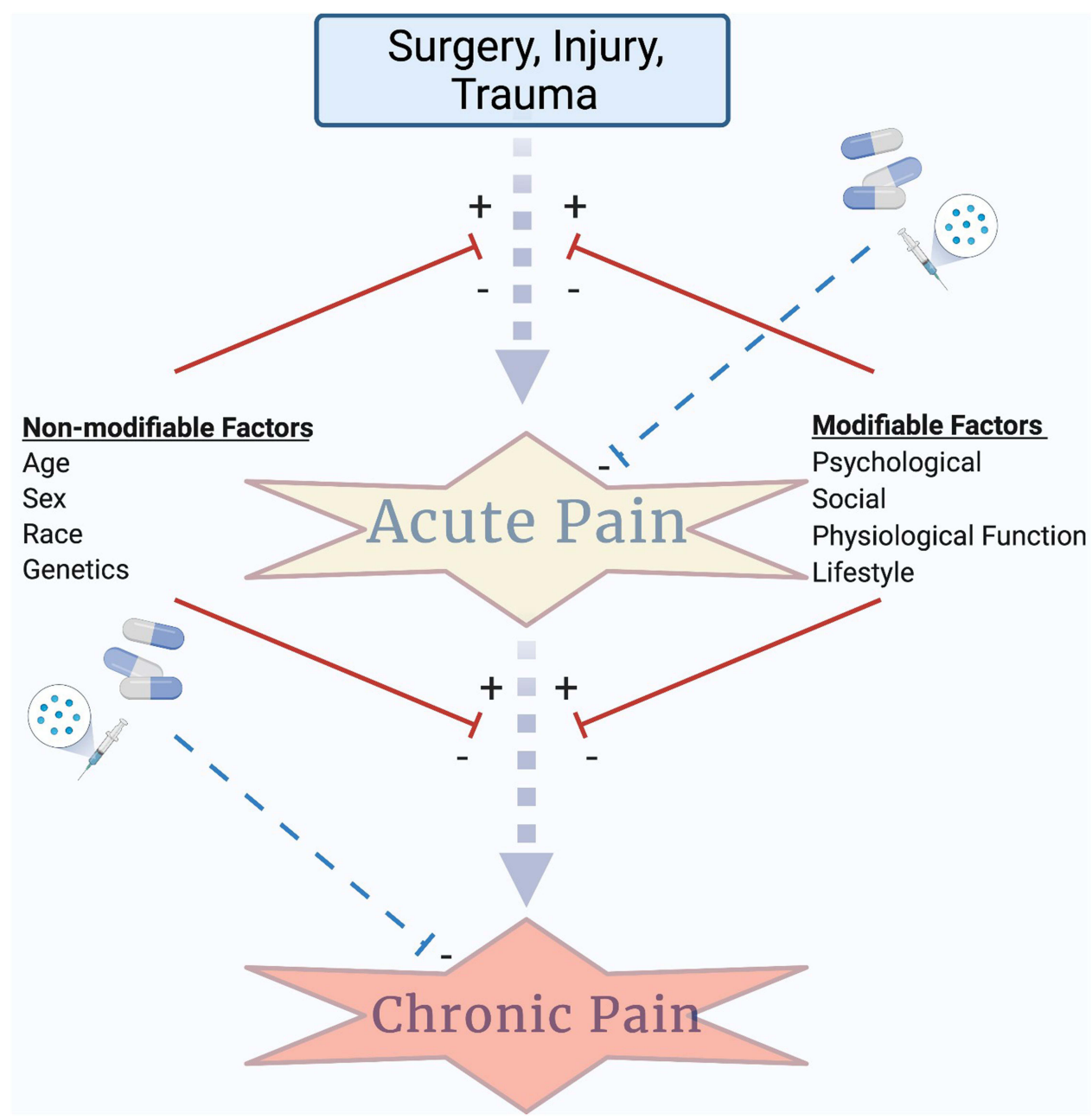

Figure I The evolution of precision pain medicine depends on identification of the risk factors and modulating variables that contribute to acute pain burden and the risk for transition to chronic pain. We highlight the contributions of two broad categories of factors, modifiable and non-modifiable, that contribute to risk for transition from acute to chronic pain. The combination of factors may provide insight into a patient's individual profile of risk for transitioning to chronic pain and point to novel pain therapeutic strategies designed to target individual mechanisms of risk. Anesthesia/analgesia can control acute pain (a primary risk factor for the development of chronic pain) and may also be used to treat chronic pain; however, efficacy can be affected by genetic factors and these should be integrated into any precision pain medicine approach. Created with BioRender.com. 
It is well known that anxiety and depression are two of the strongest predictors for the transition from acute to chronic pain. ${ }^{7}$ There is also evidence that high levels of anxiety and stress can reduce a patient's analgesic response to opioids. ${ }^{7}$ This has been well studied in rheumatological diseases, where it was found that pain catastrophizing along with depression played a larger role in a patient's subjective pain score than did objective radiographic evidence of disease. ${ }^{7}$ Phenotyping can be useful for risk stratification of poor perioperative outcomes. Patients with higher pre-surgical anxiety scores have been found to have worse analgesic outcomes following total knee or total hip replacements. ${ }^{8}$ One of the wellvalidated questionnaires recommended to determine the presence of depression and anxiety is the Hospital Anxiety and Depression (HADS) scale. ${ }^{9}$ There is evidence that patients with higher HADS scores not only show a poorer response to opioids but also possess a greater incidence of opioid misuse. ${ }^{10,11}$ Besides mood problems, having a positive or negative affect can influence chronic pain experiences and outcomes. Positive affect refers to a feeling state where pleasant moods and emotions promote positive approach-oriented behaviors and impart a sense of relaxation and contentment. Multiple studies have shown correlations between the presence of or interventions to promote a positive affect and improved outcomes for patients with chronic pain. ${ }^{12-14}$ Multiple well-validated questionnaires are used to assess positive and negative affect including the Patient-Reported Outcomes Measurement Information System (PROMIS) pain interference questionnaire and the Positive and Negative Affect Schedule. ${ }^{15}$ Multiple studies have shown a correlation between negative affect and a poor analgesic response to epidural steroid injections in the treatment of low back pain, which highlights that assessing this construct may help predict outcomes for pain interventional procedures. $^{16,17}$

Pain catastrophizing is another phenotypic maladaptive coping trait that has shown correlation to the development of chronic pain and influences response to pain treatments. Pain catastrophizing involves magnification, rumination, and helplessness. There is a large body of evidence that the presence of pain catastrophizing, which can be assessed by the Pain Catastrophizing Scale, plays a pivotal role in musculoskeletal pain. ${ }^{18}$ If present, it is a strong pre-surgical predictor of a poor outcome. ${ }^{19}$ Catastrophizing has also been shown to limit the response to standard therapies like cortisone, acetaminophen, and tramadol. ${ }^{20}$ A recent meta-analysis by Schutze et al indicated the 3 best treatment tools for the management of pain catastrophizing to be cognitive behavioral therapy, acceptance and commitment therapy, and physical therapy. ${ }^{21}$ When examining the correlations between psychological factors and the development and/or maintenance of chronic pain, it is easy to understand why this knowledge would be extremely useful when managing patients. This understanding would make it possible to optimize patients' psychological conditions prior to undergoing surgery and develop an opioid-sparing multi-modal analgesic plan in the preoperative setting. Other maladaptive coping traits to chronic pain that have been associated with negative chronic pain outcomes include kinesiophobia (fear of movement), ${ }^{22,23}$ poor self-efficacy, ${ }^{24-26}$ and injustice. ${ }^{27,28}$ However, phenotyping and predictive tools to identify these psychosocial indicators in addition to interventions aimed at treating pain and modulating these characteristics have been shown to provide improved outcomes for chronic pain patients. ${ }^{29-36}$

The presence of sleep disturbances is another important psychological determinant of health. It is well known that sleep disturbances and chronic pain frequently coexist. A large percentage of patients with chronic pain experience some form of sleep disorder. This relationship creates a paradoxical problem because, as a patient becomes more fatigued, their pain intensity rises and their ability to reduce pain is suppressed. ${ }^{37,38}$ Alsaadi et al found that the probability of developing a sleep disorder increased by $10 \%$ for each point increase on the Visual Analog Scale (VAS) ${ }^{39}$ As chronic pain and sleep disturbances work in tandem, this relationship should be utilized as a marker for health in order to provide a risk assessment for the development of pain. First, it is important to identify if the patient expresses any signs or symptoms of sleep disturbances with the use of questionnaires, including the validated Pittsburgh Sleep Quality Index (PSQI) score ${ }^{40}$ and the Insomnia Sleep Index. ${ }^{41}$ Karaman et al discovered that the presence of chronic pain was associated with significantly higher PSQI scores versus those without chronic pain. ${ }^{42}$ These scores were also noted to be even higher in males versus females. ${ }^{42}$ There is also evidence that patients suffering from sleep deprivation have a better response to the medication pregabalin than opioid medications like codeine. ${ }^{43}$ Having access to this information provides alternative targets like sleep hygiene and may aid in drug selection like pregabalin. Table 2 shows 
Table 2 Validated Instruments to Screen for Psychological Factors Affecting Pain

\begin{tabular}{|l|l|l|l|}
\hline $\begin{array}{l}\text { Psychological } \\
\text { Factors }\end{array}$ & Validated Test & Pain-Related Findings & $\begin{array}{l}\text { Response to Patients Screening Positive } \\
\text { for Psychological Factors }\end{array}$ \\
\hline $\begin{array}{l}\text { Anxiety/ } \\
\text { Depression }\end{array}$ & $\begin{array}{l}\text { Hospital, Anxiety and } \\
\text { Depression Scale (HADS) } \\
\text { Depression, Anxiety and } \\
\text { Stress scale (DASS) }\end{array}$ & $\begin{array}{l}\text { Decreased opioid response, reduced response } \\
\text { to epidural steroid injections }\end{array}$ & Cognitive Behavioral Therapy \\
\hline Catastrophizing & Pain Catastrophizing Scale & Predicts poor surgery outcome & $\begin{array}{l}\text { CBT/Acceptance and Commitment therapy, } \\
\text { Physical Therapy }\end{array}$ \\
\hline $\begin{array}{l}\text { Sleep } \\
\text { disturbance }\end{array}$ & $\begin{array}{l}\text { Pittsburgh Sleep Quality } \\
\text { Index (PSQI) }\end{array}$ & $\begin{array}{l}\text { Worsens pain score, reduced response to } \\
\text { opioids }\end{array}$ & $\begin{array}{l}\text { Cognitive Behavioral Therapy Insomnia (CBT- } \\
\text { I) }\end{array}$ \\
\hline
\end{tabular}

validated instruments that can be used to screen for psychological factors affecting pain.

\section{Social Factors}

The paradigm of chronic pain also includes social factors in addition to psychological factors as described above. Social factors that are routinely studied in relation to chronic pain include: social support, social isolation, satisfaction with social roles, and social responses to pain behaviors. $^{44}$ Social support, and even perceived social support, has been positively correlated with better pain outcomes such as pain severity and improved overall functioning. ${ }^{44-47}$ In a recent study of older adults with chronic pain, perceived social support was found to moderate the association between pain intensity and depressive symptoms. ${ }^{48}$ In another study, perceived co-worker and supervisor support was predictive of a clinically relevant and functional recovery in army workers with non-acute and non-specific low back pain. ${ }^{49}$ Social isolation is another construct that has been found to influence chronic pain and its downstream outcomes. In a study by Leung et al, social isolation was determined to be an important factor in not only the evolution of chronic pain in elderly individuals but was also associated with its onset. ${ }^{50}$ It is also important to understand how the nature of other important social interactions, such as those surrounding employment, may influence chronic pain and chronic pain outcomes. Dissatisfaction with co-workers and lack of social support at work are among the predictors for pain-related work disability. ${ }^{51,52}$ The social environment can also be utilized for adaptive purposes. Social support in the form of encouragement to complete tasks was negatively associated with pain-related disability. ${ }^{53}$ Furthermore, educating and training loved ones and spouses in assisting with pain-related coping skills has been shown to improve functioning and self-efficacy in managing pain symptoms. ${ }^{54,55}$ To assess social constructs for patient pain phenotyping, multiple validated tools are available including the PROMIS Social Health profile which includes 7 domains: instrumental social support, emotional social support, informational social support, companionship, satisfaction in participation in social roles, social isolation, and self-perceived ability to participate in social roles and activities.

\section{Physiological Factors}

Physiological factors include phenotypic indicators (eg, pain intensity, severity, location, and descriptors) as well as functional biomarkers of pain/sensory function assessed using quantitative sensory testing (QST), neuroimaging, and conditioned pain modulation (CPM). A biomarker is any characteristic that is objectively measured and evaluated as an indicator of normal biological processes, pathogenic processes, or pharmacologic response to a therapeutic intervention. ${ }^{56}$ While no single "pain biomarker" has been identified, a panel of measures may allow for a comprehensive assessment of risk for chronic pain development and/or help predict treatment response. ${ }^{57}$ QST, neuroimaging, and CPM may serve as biomarkers by offering insights into the neurobiological processing changes that support the transition from acute to chronic pain as well as the efficacy of treatments designed to prevent this transition.

Baseline pain has classically been examined by having patients fill out questionnaires at set intervals of time, which relies on recall over a period of days, weeks, and months. Newer and possibly more accurate ways to identify baseline pain variability include patient journaling or 
diaries. This allows patients to write down or electronically submit changes to their pain score in real time, eliminating the need to recall which can potentially lead to errors. Extensive effort has been placed in the development of electronic diaries for real-time symptom documentation. While there has been no difference seen in the ease of use between paper and electronic diaries, some studies have indicated patient preference and willingness to continue using electronic diaries over paper. ${ }^{58}$ Handheld applications that could be downloaded to a smartphone or tablet could easily be taken with patients wherever they go, whereas they may be less likely to bring a written pain diary with them. The other advantage electronic diaries provide is the ability to present real-time data to the provider in order to make more frequent adjustments and recommendations regarding activity level and/ or medication doses/changes. So far, there is no research showing improvement in pain management from the use of electronic pain trackers and their ability to make frequent adjustments to care; however, this should be an area of focus in the future.

For mechanistic characterization of pain, questionnaires like the Short Form McGill Pain Questionnaire, ${ }^{59}$ Pain Quality Assessment Scale, ${ }^{60}$ and PainDETECT ${ }^{61}$ can be useful. These questionnaires allow patients to describe the type of pain they are having. Examples of pain descriptors include burning, heavy, paroxysmal, lightning, and sharp. There is evidence of improved response to pregabalin than placebo when pain was described as deep, electrical, or burning. ${ }^{62}$ Neuropathic pain as a whole has a potential of being utilized as a phenotypic predictor. After determining that a patient has neuropathic pain, one can assess the sensory abnormality they are experiencing as a result by using the Neuropathic Pain Symptom Inventory (NPSI). ${ }^{63}$ Patients with high NPSI scores showed equal responses to duloxetine and pregabalin, however those with lower NPSI scores had a large variation between the two drugs. ${ }^{63}$

QST is a collection of methods designed to measure patient response to various stimulation (eg, mechanical, thermal, cold, pressure) in order to evaluate somatosensory function as well as identify the nature/presence of hyperalgesia and allodynia. ${ }^{64,65}$ It is most commonly utilized to evaluate neuropathic pain conditions. The protocol with the best validation is the German Research Network on Neuropathic Pain (DFNS) battery, which can help determine detection and pain thresholds to both mechanical and thermal stimulation in addition to assessing for wind up pain. ${ }^{66,67}$ Following completion of this protocol, patients can be assigned a profile. Previous research in this area has shown that QST profiles can have tremendous overlap between different neuropathic conditions, indicating that the profile is not pain syndrome-specific but patientspecific, thus hopefully allowing for individualized treatment regimens. ${ }^{68-70}$ This was modeled by Demant et al when they showed improved treatment of neuropathic pain with hyperalgesia (sensory gain) using the sodium channel blocker oxcarbazepine vs minimal benefit in patients with neuropathic pain and sensory loss. ${ }^{71}$ There has been a variety of research released within the past few years on the use of QST. One study found a correlation between the treatment response to botulinum toxin and thermal sensation in post-herpetic neuralgia, such that patients received greater benefit from botulinum toxin if they were found to have intact thermal sensation on QST prior to treatment. ${ }^{72}$ Another study examined patients with pain following spinal cord injury. Results showed increased response to pregabalin if thermal sensation was intact and minimal benefit when thermal sensation was lost. $^{73}$ With these studies in mind, QST could form a critical pillar in the development of treatment regimens. With that said, time will need to be addressed as a primary limiting factor for implementation in the clinical setting, as the DFNS-QST is a rather lengthy test that averages 1-3 hours per patient. ${ }^{74}$ Attempts at simplifying QST batteries for administration in the clinical setting have been reported and have shown that a variety of simple bedside tools (ice cubes, pinprick, cotton swabs) can reliably be used to quantify numerous QST parameters. ${ }^{75-79}$ Further research is warranted via large multi-center trials in order to investigate whether bedside QST batteries can predict response to and improve pharmacologically directed therapies.

CPM and temporal summation are two other categories of sensory testing that may serve as specific phenotypic markers of centralized pain conditions. CPM describes the body's ability to use one noxious stimulus to inhibit or reduce the response to another. ${ }^{80}$ This phenomenon is referred to as diffuse noxious inhibitor control. ${ }^{81}$ It is believed to involve opioid, serotonergic, and noradrenergic pathways. ${ }^{82}$ The effectiveness of CPM can be tested by applying a noxious stimulus alone and in the presence of sustained stimulation. If CPM is functioning effectively, the pain from the original noxious stimulus should be reduced in the presence of a coexisting tonic stimulus. ${ }^{83}$ This was studied by Yarnitsky et al, who found that patients with a poorly functioning CPM had a much better 
response to duloxetine in the treatment of diabetic peripheral neuropathy than those with properly functioning $\mathrm{CPM}^{84}$ Temporal summation, which is the increased perception of pain when an identical noxious stimulus is repeated, is also being studied. Patients with chronic pain conditions often exhibit higher levels of temporal summation. ${ }^{82}$ While there have been few large multicenter studies conducted on this phenomenon, it is believed that it can be utilized as a predictor of the development of chronic pain following surgery. ${ }^{85}$

Neuroimaging is another physiological assessment tool being utilized by researchers to identify neurobiologic mechanisms underlying chronic pain. As neuroimaging has advanced over the years, we have come to understand that pain perception and modulation is an extremely complex pathway involving multiple structures in the central nervous system (CNS). Multiple chronic pain states including fibromyalgia, chronic low back pain, osteoarthritis (OA), and complex regional pain syndrome (CRPS) have been studied utilizing neuroimaging modalities. The most commonly utilized modality is functional magnetic resonance imaging (fMRI), which can assess the activity and connectivity of different regions of the brain by detecting blood oxygen levels. ${ }^{86}$ This can be done while the patient is at rest (resting state fMRI), performing a task, or with an evoked painful stimulus. Researchers have utilized functional neuroimaging to study changes in connectivity in multiple structures throughout the CNS including the primary somatosensory cortex, posterior insular cortex, thalamus, amygdala, hippocampus, and basal ganglia. Alterations consistent with increases in pro-nociceptive connectivity and decreases in anti-nociceptive connectivity have been found. ${ }^{87-93}$ Few studies have been performed to investigate how interventions affect neuroimaging signatures pre- and post-intervention, but these and future studies may lead to findings that allow for the use of this modality to influence precision pain medicine. ${ }^{94-100}$

Two other imaging modalities used are proton magnetic resonance spectroscopy (H-MRS) and positron emission tomography (PET). H-MRS can be used in order to determine the changes of pain-regulating neurotransmitters like GABA and glutamate. Clinical studies have shown an increased level of glutamate on H-MRS scans in patients with fibromyalgia compared to healthy controls. ${ }^{101}$ PET scans are currently being utilized to evaluate opioid receptor density and binding capacity which may influence a patient's response to opioid medications. These types of imaging modalities show great promise for influencing precision medicine. ${ }^{101}$ This evidence further supports the complexity of chronic pain and the drastic alterations it can cause to the CNS. By utilizing neuroimaging to identify which CNS structures are altered, patients can be further categorized beyond a chronic pain or fibromyalgia diagnosis, and mechanisms-based research can be performed in the hope that it may direct more targeted treatment regimens and direct appropriate drug dosing. ${ }^{102,103}$ Understanding CNS alterations will also help select patients for appropriate clinical trials in order to further advance the future study of precision medicine.

\section{Genetic Factors}

Individual differences in the DNA sequence (genetics) and the structure of the genome (epigenetics) are estimated to account for up to $70 \%$ of the individual differences in pain sensitivity and susceptibility to chronic pain conditions ${ }^{104-108}$ in addition to affecting the response to pain-relieving treatments (eg, pharmacogenetics). Individual differences in the DNA sequence are now being used in various subspecialties to assess risk for disease, disease progression, and other relevant health outcomes. ${ }^{109,110}$ Incorporating genetics and epigenetic analysis into practice provides physicians the opportunity to tailor treatment regimens to specific disease processes, maximize drug efficacy, and minimize unnecessary adverse reactions without trial and error. ${ }^{109}$

Single nucleotide polymorphisms (SNPs) are the most common variants and represent differences in the nucleic acid sequence at a given genomic location (ie, alleles) between individuals. The major allele is present in most of the population, and the less common (ie, minor) allele frequency varies but occurs in greater than $1 \%$ of the population. ${ }^{111,112}$ This type of genetic variation occurs approximately every 1000 th nucleotide, so it is estimated that there are roughly 4-5 million SNPs in the human genome contributing to the significant phenotypic variation across the population. Copy number variation (CNV), on the other hand, is a variation in the number of gene copies an individual carries relative to the baseline of two copies, one on each chromosome. While the role of SNPs and CNVs in pain susceptibility and/or painful disease progression still remains to be fully understood, there are well-known associations between these variations and treatment response that are already driving precision medicine approaches in other fields including cardiovascular medicine, ${ }^{113,114}$ rheumatology, ${ }^{115}$ and oncology. ${ }^{116}$ While not explicitly related to precision pain management, genetic analysis is beginning to be applied by 
anesthesiologists, most often to predict the risk for relatively rare conditions that can develop during anesthesia exposure. One application that has become more common is the use of genetic analysis for prediction and treatment of prolonged paralysis/apnea following succinylcholine administration in patients with genetic variations in $B C H E$, the gene encoding butyrylcholinesterase (BCHE). More than 60 genetic variations have been identified in $B C H E$, affecting the quantity and quality (eg, enzymatic effectiveness) of the BCHE produced. ${ }^{117}$ Currently, BCHE genetic testing is typically ordered only after a patient or close genetic relative has reported an episode of extended paralysis following succinylcholine. In addition, the Clinical Pharmacogenetics Implementation Consortium (CPIC) has also issued guidelines regarding the identification of "diagnostic mutations" within CACNA1S (encoding the calcium voltage-gated channel subunit alpha 1 $\mathrm{S}$ (CACNAIS)) or RYRl (encoding ryanodine receptor 1 (RYRI)) genes responsible for the emergence of malignant hyperthermia $(\mathrm{MH})$ following exposure to volatile anesthetics or the depolarizing muscle relaxant succinylcholine. ${ }^{118}$ Most often, diagnostic and genetic testing follows an episode of $\mathrm{MH}$, but the identification of individuals with $\mathrm{MH}$ through genetic testing could significantly reduce the relatively high morbidity $(35 \%)^{119}$ and mortality $(12 \%)^{120}$ of an $\mathrm{MH}$ episode. In this way, the technology for detecting genetic variations has become commonplace, but the translational application of this knowledge to predict anesthesia-related outcomes is only beginning to be used to improve drug efficacy and eliminate adverse reactions in the clinical setting.

Pharmacogenetics could be applied to decrease opioid use for pain in a number of ways, including assisting in prediction of a patient's opioid analgesic response and individual opioid use disorder risk. Physicians have commonly relied on medications like morphine and oxycodone in the acute/post-surgical setting, but they come with a significant side effect profile and risk of tolerance and abuse. Both SNPs and CNVs are seen in the CYP2D6 gene encoding the hepatic enzyme cytochrome P450 family 2 subfamily D member 6 (CYP2D6), a key enzyme in the metabolism of $\sim 25 \%$ of clinically used drugs, including the opioid medications codeine and tramadol. CYP2D6 is responsible for metabolizing these drugs into their biologically active metabolites, a conversion process that is required for the patient to receive optimal analgesic benefit. ${ }^{121}$ This combination of SNPs and CNVs results in patient phenotypes ranging from poor drug metabolizers (low enzymatic activity) to ultrarapid metabolizers (very high enzymatic activity), ${ }^{122}$ and can greatly impact the analgesic and side effect response to opioid medications. ${ }^{123}$ Understanding the opioid metabolic profile allows the physician to avoid medications when they are unlikely to be effective and/or safe. If opioids are deemed to be the optimal choice for pain management, such as in cancer-related pain, application of pharmacogenetics could help determine the most appropriate opioid and dosage based on patient genotype and the associated metabolic phenotype. ${ }^{124}$

Understanding the genetic profile of the CYP enzymes also provides opportunities for increasing precision in the use of non-opioid pain medications. Amitriptyline, a commonly utilized medication in pain management, undergoes metabolism by CYP2D6 as well as another member of the cytochrome P450 family, CYP2C19, encoded by the CYP2C19 gene. If a patient is a known poor metabolizer of amitriptyline, based on CYP2D6 and/or CYP2C19 genotype, then their treatment dose only needs to be about $50 \%$ of the standard dose. ${ }^{125,126}$ However, if they are a rapid or ultrarapid metabolizer, then the recommendation is to avoid the use of amitriptyline or to administer roughly $110 \%$ of the standard treatment dose. ${ }^{121,127}$ It is not only the analgesic efficacy of a drug that should be considered, but also the risk for adverse effects. More recently, this approach has been used in the specific therapeutic recommendations for avoiding adverse effects resulting from a non-steroidal anti-inflammatory drug (NSAID) by evaluating a patient's risk by $C Y P 2 C 9$ genotype ${ }^{128}$ and the half-life of the NSAID prescribed. NSAIDs act by inhibiting COX-1 and/or COX-2, both of which play a role in prostaglandin production. ${ }^{129}$ The adverse effects of NSAIDs include gastrointestinal bleeding, cardiovascular complications, and kidney damage, and risk increases with the dose administered and length of exposure. ${ }^{130-132}$ While guidelines vary depending on half-life of the specific NSAID under consideration, recommendations broadly advise that individuals with normal CYP2C9 enzymatic activity levels (normal metabolizers) can tolerate a typical dosing regimen (prescription or non-prescription) while dosing, and duration should be reduced or avoided entirely in those with intermediate or poor metabolic phenotypes, respectively. ${ }^{128}$ Knowledge of a patient's non-opioid genetic metabolism profile can allow the physician to prescribe the adequate treatment dose, while likely circumventing unnecessary medication adverse effects -the fourth leading cause of death in the United States. ${ }^{121}$ 
There are several genes where SNP genotype has been associated with differences in pain severity or risk for development of a chronic pain condition. A comprehensive summary of these genes and variations would be outside the scope of the current review but has been presented elsewhere. ${ }^{133}$ The relationship between pain susceptibility and variations within these genes may help to identify patients who are at risk for disproportionately severe pain or who are most likely to develop chronic pain. These relationships could not only help to identify those patients at the highest risk for pain but also point to specific targets for novel precision pain therapeutic development designed to address the underlying mechanism of risk. Arguably, the most welldefined example in this category of "pain genes" is COMT, encoding the enzyme catechol-o-methyltransferase (COMT) responsible for the breakdown of catecholamines. ${ }^{134,135}$ COMT SNP genotype is associated with the altered sensitivity to painful stimuli as well as the development of chronic pain conditions (eg, fibromyalgia, chronic widespread pain, irritable bowel syndrome, migraine headache) and may contribute to individual differences in morphine analgesic efficacy. ${ }^{136}$ COMT genotype is not currently being used to inform precision pain management in the clinical setting but, moving forward, it may help to identify patients at the highest risk of developing chronic pain after interventions like surgery and chemotherapy. Members of the family of voltage gated sodium channels responsible for action potential generation and propagation within pain-sensitive neurons include $S C N 8 A-S C N 11 A$, encoding $\mathrm{Na}_{\mathrm{v}} 1.6, \mathrm{Na}_{\mathrm{v}} 1.7, \mathrm{Na}_{\mathrm{v}} 1.8$, and $\mathrm{Na}_{\mathrm{v}} 1.9$ respectively. Variations within these genes ${ }^{137}$ were first implicated in monogenic disorders of altered pain sensitivity (eg, congenital insensitivity to pain, familial episodic pain syndromes, inherited erythromelalgia, and paroxysmal extreme pain disorder), ${ }^{138,139}$ but more recently associations have been identified for pain sensitivity in nonpathologic individuals ${ }^{140-143}$ and risk of developing chronic pain conditions. ${ }^{140}$ While genotyping for this group of genes is not currently being used clinically outside of diagnosis for monogenic disorders, the genetic and functional validation of these channels in human pain has led to the development of selective sodium channel inhibitors to replace traditional local anesthetics. ${ }^{144-147}$ In the future, the selection of sodium channel selective molecules could be tailored to the procedure as well as the patient's genotype to improve pain outcomes.

Pharmacogenetics has, historically, focused on variations within the genomic DNA sequence associated with patient medication response. The related field of epigenetics focuses on alterations in gene expression that are not the result of alterations to the genomic DNA sequence, but still affect patient outcomes through control of gene expression and downstream end product availability. The epigenome encompasses the heritable components of the genome outside of the DNA sequence, which are involved in regulating gene and protein expression. To this end, individual differences have been noted in DNA methylation, histone acetylation, and histone deacetylation. DNA methylation and histone modifications exert critical control over the chromatin structure of the genome $^{148-151}$ to either promote or inhibit gene expression. ${ }^{151,152}$ Health-care professionals use differences in gene and protein end-products expression to assess for specific disease states (eg, increased circulating CRP or decreased insulin), but incorporating epigenetics could help to unravel the mechanisms by which altered gene expression occurs and, potentially, shed light on how to harness that underlying process to improve patient health.

In largely preclinical research, epigenetic modifications have been implicated in susceptibility to chronic pain and as a therapeutic target to prevent/treat pain. In rat models of both inflammatory and neuropathic pain, expression of histone deacetylase enzymes (HDACs) is positively correlated with the hypersensitivity; a phenomenon that is reversible with HDAC inhibitors including baicalin, valproic acid, and suberanilohydroxamic acid. ${ }^{152-155}$ There have also been correlations made between histone acetylation and opioid receptor expression. Studies using mouse models have shown that neuropathic injury is also associated with histone- 4 acetylation, thereby enhancing activity of neuron-restrictive silencer factor (NRSF) and suppressing expression of OPRM1, which is responsible for the production of $\mu$-opioid receptors; however, HDAC inhibition blocked OPRM1 suppression by NRSF. ${ }^{156}$ Hypermethylation of DNA CpG islands has been implicated in the incidence and severity of cancer-induced chronic pain via the increased production of endothelin1 , which has pro-nociceptive properties. ${ }^{157}$

Importantly, while we have focused primarily on the inherited aspects of epigenetics, the literature suggests methylation and histone modifications are both nonmodifiable (ie, from parental chromosome donation at conception) and sensitive to modification across the lifespan due to environmental or lifestyle factors. Epigenetic modifications may be engaged in the perioperative period and serve as a key component linking acute surgical pain to chronic pain. Elevated levels of glucocorticoids released 
during the perioperative period secondary to the stress of surgery have the ability to disrupt DNA methylation, releasing key genes from transcriptional repression. This can result in $\mathrm{C}$-fiber dysfunction, increased levels of pain promoting neurotransmitters, and altered responsiveness to morphine. $^{158,159}$ While the incorporation of epigenetics, and genetics more broadly, into evidence-based practice shows great promise, future studies are needed to identify the most clinically relevant modifications for pain and analgesia and develop strategies for use in precision diagnostic and treatment algorithms as well as non-opioid targeted therapies.

\section{Cancer-Related Pain}

While precision medicine has helped change the landscape of cancer research and treatment, there has been far less application towards the management and treatment of cancer-related pain. Cancer-related pain places significant burdens on a high percentage of patients and, unfortunately, less than half of patients who suffer from pain will obtain adequate relief. ${ }^{160}$ Current guidelines for the treatment of cancer-related pain include the World Health Organization analgesic ladder, which begins with non-opioid medications like NSAIDs for mild pain and progresses to opioids \pm nonopioids as pain becomes moderate to severe. ${ }^{161}$ While this provides a good framework for treating and managing pain, it does not include specific guidance on opioid selection and dosing or interventional options.

Pharmacogenetics has the potential to improve guidance in dosing and drug selection. For instance, focusing on SNPs of genes like $O P R M 1$, where it is well known that patients possessing one or more $G$ alleles have decreased transcription of opioid receptors as well as response to opioid binding, may help improve starting doses as well as titration. ${ }^{162}$ Additionally, one multicenter cross-sectional study investigated alterations in CYP2D6 genotyping and pain management in cancer patients with oxycodone, but found no difference in pain scores despite showing significant differences of oxycodone metabolites including oxymorphone. ${ }^{163}$ While this study did not show a difference in pain scores, there may be a benefit for a drug selection that has not been studied.

While half of patients with cancer-related pain have insufficient pain control, $25 \%$ continue to suffer from inadequate pain control at death. ${ }^{164}$ With suffering so high, it is important to recognize that interventional therapies in addition to medications may be necessary. A patient's pharmacogenetic profile may indicate that they are a poor candidate for medical therapy alone, in which case a referral to a pain specialist may be beneficial for evaluation of nerve blocks, neuromodulation, and intrathecal drug delivery.

The impact of the biopsychosocial model of pain has been applied to cancer-related pain, and the present data may be helpful to clinicians providing precision pain medicine care to cancer patients with pain. Among cancer patients, much research has demonstrated the importance of psychosocial factors in the experience of pain. Individuals with cancer experience higher rates of psychosocial distress after their diagnosis and during their cancer treatment, and anxiety and depression have historically been reported as correlated with greater pain severity and poor pain outcomes. ${ }^{165,166}$ However, in a recent publication of a large cohort of cancer patients with chronic cancer-related pain $(\mathrm{n}=700)$, it was found that pain catastrophizing and sleep disturbance were consistently associated with elevated pain symptoms. ${ }^{167}$ This correlation of increased pain severity and poor pain outcomes has been corroborated by other groups. ${ }^{168}$ The impact of social constructs on pain and pain outcomes in cancer pain has been reported in a recent meta-analysis that identified that social support has been found to be associated with less postoperative pain after breast cancer surgery. ${ }^{169}$ Furthermore, the presence of a strong social support network is associated with reduced cancer pain symptom burden, improved quality of life, and reduced distress in patients with chronic lymphocytic leukemia, ${ }^{170}$ breast cancer, ${ }^{171,172}$ and colorectal cancer. ${ }^{173}$ Emerging research is also being performed to identify how physiologic pain processing parameters may correlate with pain outcomes in breast cancer surgery patients. In a study by Schreiber et al, it was found that breast cancer surgery patients who had reduced pain pressure thresholds and higher pain ratings after pinprick temporal summation had associations with the development of post-mastectomy pain syndrome. ${ }^{174}$ Further research in this and other cancer pain populations is warranted to determine if QST is a strong predictive parameter in providing precision pain management to cancer patients.

\section{Limitations of the Field}

Precision pain medicine offers the promise of a novel set of solutions to the problem of chronic pain, through mechanism-focused prevention and individualized riskfocused treatment strategies. Unfortunately, the current state of the science is still focused on identification of the critical factors that make up the patient's profile of risk. Precision medicine is dependent on data, but that data 
also constitute one of the primary areas of concern in the field of precision healthcare. Large volumes of highly specific patient data must be managed appropriately to protect patient privacy. In addition to protecting patient data, access to precision pain management strategies must not be restricted on the basis of financial means or socioeconomic status. In fact, given that the impact of psychological, physiological, and genetic factors could have differential impact on chronic pain risk based on race, ethnicity, sex, and other socioeconomic factors, the application of new findings to diverse groups must be based on evidence-based medicine and not on the assumption that all groups will benefit equally from precision pain management strategies that work for others. Currently, the integration of pharmacogenetics/genomics, nuanced phenotyping, and neuroimaging require the availability of significant infrastructure (eg, clinical expertise, equipment, facilities), but as the cost for these resources decreases and education for their application is more effectively integrated into medical training, they should become more widely used to benefit patients and reduce suffering.

Another limitation includes who is managing pain. While the number of pain centers using multimodal assessment and treatment strategies grew in the 20th century, survey data suggest that only $15 \%$ of people living with pain have accessed specialty pain management services and more than $50 \%$ of pain management is happening in primary care settings. ${ }^{175}$ While there has been significant progress made in the assessment and treatment of pain within these centers of expertise, the successful application of precision pain medicine for the masses depends on integration of these approaches into primary care as well as pain medicine.

\section{Limitations of the Present Study}

The goal of the present review was to provide a comprehensive overview of precision medicine as it pertains to the field of chronic pain management. While we focused on many areas that are known to be important in the field of precision medicine, we understand that a limitation of the present review is that not all biomarkers and phenotyping parameters were able to be included. Additionally, while many chronic noncancer and cancerrelated precision pain data have been presented, we recognize that there may be additional research on other pain syndromes that were not included. A strength of these limitations is that further narrative, scoping, or systematic reviews should be pursued given the importance and timeliness of the topic.

\section{Moving Forward}

Chronic pain continues to be a growing public health problem, requiring significant financial and health-care resources annually while negatively impacting the wellness and quality of life of millions. Identification of patient risk profiles by incorporating genetic and phenotypic data is key to the development of precision pain and analgesic medicine strategies. The evidence is clear that pain is an individualized experience and personalized and/or precision treatments could improve pain outcomes. As of this moment, however, we are still in the discovery phase with the goal of moving into evidence-based practice in the coming years. Once we have a clear understanding of the mechanisms that drive pain, we can then progress beyond the basic diagnosis and treatment of symptoms to the management of the underlying pathophysiology.

\section{Acknowledgments}

The authors would like to acknowledge Walter Orr, MPH, for technical writing and editorial assistance and manuscript preparation. The authors thank Doug Wright, $\mathrm{PhD}$, for technical assistance with producing the figure.

\section{Funding}

AC receives funding through the National Institutes of Health National Institute of General Medical Sciences, K23GM123320.

\section{Disclosure}

The authors report no conflicts of interest or sources of financial support to report in relation to this work.

\section{References}

1. Simon LS. Relieving pain in America: a blueprint for transforming prevention, care, education, and research. Mil Med. 2016;181 (5):397-399. doi:10.7205/MILMED-D-16-00012

2. National Research Council Committee on a Framework for Developing a New Taxonomy of Disease. The National Academies Collection: reports funded by National Institutes of Health. In: Toward Precision Medicine: Building a Knowledge Network for Biomedical Research and a New Taxonomy of Disease. Washington (DC): National Academies Press, National Academy of Sciences; 2011.

3. The Precision Medicine Initiative. The White House archives of President Barack Obama; 2016. Available from: https://obamawhite house.archives.gov/precision-medicine. Accessed July 20, 2021.

4. Marson FAL, Bertuzzo CS, Ribeiro JD. Personalized or precision medicine? The example of cystic fibrosis. Front Pharmacol. 2017;8:390. doi:10.3389/fphar.2017.00390

5. MedLine Plus. What is the difference between precision medicine and personalized medicine? What about pharmacogenomics? U.S. National Library of Medicine; 2020. Available from: https://medlineplus.gov/ genetics/understanding/precisionmedicine/precisionvspersonalized/. Accessed July 20, 2021. 
6. Baethge C, Goldbeck-Wood S, Mertens S. SANRA - a scale for the quality assessment of narrative review articles. Res Integr Peer Rev. 2019;4:5. doi:10.1186/s41073-019-0064-8

7. Edwards RR, Cahalan C, Mensing G, Smith M, Haythornthwaite JA. Pain, catastrophizing, and depression in the rheumatic diseases. Nat Rev Rheumatol. 2011;7(4):216-224. doi:10.1038/nrrheum.2011.2

8. Duivenvoorden T, Vissers MM, Verhaar JA, et al. Anxiety and depressive symptoms before and after total hip and knee arthroplasty: a prospective multicentre study. Osteoarthritis Cartilage. 2013;21(12):1834-1840. doi:10.1016/j.joca.2013.08.022

9. Zigmond AS, Snaith RP. The hospital anxiety and depression scale. Acta Psychiatr Scand. 1983;67(6):361-370. doi:10.1111/ j.1600-0447.1983.tb09716.x

10. Jamison RN, Edwards RR, Liu X, et al. Relationship of negative affect and outcome of an opioid therapy trial among low back pain patients. Pain Pract. 2013;13(3):173-181. doi:10.1111/ j.1533-2500.2012.00575.x

11. Wasan AD, Michna E, Edwards RR, et al. Psychiatric comorbidity is associated prospectively with diminished opioid analgesia and increased opioid misuse in patients with chronic low back pain. Anesthesiology. 2015;123(4):861-872. doi:10.1097/ALN.00 00000000000768

12. Finan PH, Garland EL. The role of positive affect in pain and its treatment. Clin J Pain. 2015;31(2):177-187. doi:10.1097/AJP.00 00000000000092

13. Esteve R, López-Martínez AE, Peters ML, Serrano-Ibáñez ER, Ruiz-Párraga GT, Ramírez-Maestre C. Optimism, positive and negative affect, and goal adjustment strategies: their relationship to activity patterns in patients with chronic musculoskeletal pain. Pain Res Manag. 2018;2018:6291719. doi:10.1155/2018/6291719

14. Galvez-Sánchez CM, Reyes Del Paso GA, Duschek S. Cognitive impairments in fibromyalgia syndrome: associations with positive and negative affect, alexithymia, pain catastrophizing and self-esteem. Front Psychol. 2018;9:377. doi:10.3389/fpsyg.20 18.00377

15. Watson D, Clark LA, Tellegen A. Development and validation of brief measures of positive and negative affect: the PANAS scales. J Pers Soc Psychol. 1988;54(6):1063-1070. doi:10.1037/00223514.54.6.1063

16. Jensen TS, Baron R, Haanpää M, et al. A new definition of neuropathic pain. Pain. 2011;152(10):2204-2205. doi:10.1016/j. pain.2011.06.017

17. Karp JF, Yu L, Friedly J, Amtmann D, Pilkonis PA. Negative affect and sleep disturbance may be associated with response to epidural steroid injections for spine-related pain. Arch Phys Med Rehabil. 2014;95(2):309-315. doi:10.1016/j.apmr.2013.09.007

18. Sullivan MJL, Bishop SR, Pivik J. The pain catastrophizing scale: development and validation. Psychol Assess. 1995;7(4):524-532. doi:10.1037/1040-3590.7.4.524

19. Lewis GN, Rice DA, McNair PJ, Kluger M. Predictors of persistent pain after total knee arthroplasty: a systematic review and meta-analysis. Br J Anaesth. 2015;114(4):551-561. doi:10.1093/ bja/aeu441

20. Mankovsky T, Lynch M, Clark A, Sawynok J, Sullivan MJ. Pain catastrophizing predicts poor response to topical analgesics in patients with neuropathic pain. Pain Res Manag. 2012;17 (1):10-14. doi:10.1155/2012/970423

21. Schütze R, Rees C, Smith A, Slater H, Campbell JM, O'Sullivan P. How can we best reduce pain catastrophizing in adults with chronic noncancer pain? A systematic review and meta-analysis. J Pain. 2018;19(3):233-256. doi:10.1016/j.jpain.2017.09.010

22. Larsson C, Ekvall Hansson E, Sundquist K, Jakobsson U. Kinesiophobia and its relation to pain characteristics and cognitive affective variables in older adults with chronic pain. $B M C$ Geriatr. 2016;16:128. doi:10.1186/s12877-016-0302-6
23. Luque-Suarez A, Falla D, Morales-Asencio JM, MartinezCalderon J. Is kinesiophobia and pain catastrophising at baseline associated with chronic pain and disability in whiplash-associated disorders? A systematic review. Br J Sports Med. 2020;54 (15):892-897. doi:10.1136/bjsports-2018-099569

24. Ferrari S, Vanti C, Pellizzer M, Dozza L, Monticone M, Pillastrini P. Is there a relationship between self-efficacy, disability, pain and sociodemographic characteristics in chronic low back pain? A multicenter retrospective analysis. Arch Physiother. 2019;9:9. doi:10.1186/s40945-019-0061-8

25. Rahman A, Ambler G, Underwood MR, Shipley ME. Important determinants of self-efficacy in patients with chronic musculoskeletal pain. J Rheumatol. 2004;31(6):1187-1192.

26. Craig A, Tran Y, Siddall P, et al. Developing a model of associations between chronic pain, depressive mood, chronic fatigue, and self-efficacy in people with spinal cord injury. J Pain. 2013;14 (9):911-920. doi:10.1016/j.jpain.2013.03.002

27. Penn TM, Overstreet DS, Aroke EN, et al. Perceived injustice helps explain the association between chronic pain stigma and movement-evoked pain in adults with nonspecific chronic low back pain. Pain Med. 2020;21(11):3161-3171. doi:10.1093/pm/ pnaa095

28. Carriere JS, Sturgeon JA, Yakobov E, Kao MC, Mackey SC, Darnall BD. The impact of perceived injustice on pain-related outcomes: a combined model examining the mediating roles of pain acceptance and anger in a chronic pain sample. Clin J Pain. 2018;34(8):739-747. doi:10.1097/AJP.0000000000000602

29. Linton SJ, Boersma K. Early identification of patients at risk of developing a persistent back problem: the predictive validity of the Orebro Musculoskeletal Pain Questionnaire. Clin J Pain. 2003;19(2):80-86. doi:10.1097/00002508-200303000-00002

30. Martinez-Calderon J, Flores-Cortes M, Morales-Asencio JM, Luque-Suarez A. Conservative interventions reduce fear in individuals with chronic low back pain: a systematic review. Arch Phys Med Rehabil. 2020;101(2):329-358. doi:10.1016/j.apmr.20 19.08.470

31. Turner BJ, Liang Y, Rodriguez N, Bobadilla R, Simmonds MJ, Yin Z. Randomized trial of a low-literacy chronic pain self-management program: analysis of secondary pain and psychological outcome measures. J Pain. 2018;19(12):1471-1479. doi:10.1016/j.jpain.2018.06.010

32. Cruz-Díaz D, Romeu M, Velasco-González C, Martínez-Amat A, Hita-Contreras F. The effectiveness of 12 weeks of Pilates intervention on disability, pain and kinesiophobia in patients with chronic low back pain: a randomized controlled trial. Clin Rehabil. 2018;32(9):1249-1257. doi:10.1177/0269215518768393

33. Watson JA, Ryan CG, Cooper L, et al. Pain neuroscience education for adults with chronic musculoskeletal pain: a mixed-methods systematic review and meta-analysis. J Pain. 2019;20(10):1140.e1141-1140. e1122. doi:10.1016/j.jpain.2019.02.011

34. Bennell KL, Nelligan R, Dobson F, et al. Effectiveness of an internet-delivered exercise and pain-coping skills training intervention for persons with chronic knee pain: a randomized trial. Ann Intern Med. 2017;166(7):453-462. doi:10.7326/M16-1714

35. Niknejad B, Bolier R, Henderson CR, et al. Association between psychological interventions and chronic pain outcomes in older adults: a systematic review and meta-analysis. JAMA Intern Med. 2018;178(6):830-839. doi:10.1001/jamainternmed.2018.0756

36. Nash VR, Ponto J, Townsend C, Nelson P, Bretz MN. Cognitive behavioral therapy, self-efficacy, and depression in persons with chronic pain. Pain Manag Nurs. 2013;14(4):e236-e243. doi:10. 1016/j.pmn.2012.02.006

37. Edwards RR, Almeida DM, Klick B, Haythornthwaite JA, Smith MT. Duration of sleep contributes to next-day pain report in the general population. Pain. 2008;137(1):202-207. doi:10.10 16/j.pain.2008.01.025 
38. Finan PH, Goodin BR, Smith MT. The association of sleep and pain: an update and a path forward. J Pain. 2013;14 (12):1539-1552. doi:10.1016/j.jpain.2013.08.007

39. Alsaadi SM, McAuley JH, Hush JM, et al. Poor sleep quality is strongly associated with subsequent pain intensity in patients with acute low back pain. Arthritis Rheumatol. 2014;66(5):1388-1394. doi:10.1002/art.38329

40. Buysse DJ, Reynolds CF, Monk TH, Berman SR, Kupfer DJ. The Pittsburgh Sleep Quality Index: a new instrument for psychiatric practice and research. Psychiatry Res. 1989;28(2):193-213. doi:10.1016/0165-1781(89)90047-4

41. Morin CM, Belleville G, Bélanger L, Ivers H. The Insomnia Severity Index: psychometric indicators to detect insomnia cases and evaluate treatment response. Sleep. 2011;34(5):601-608. doi:10.1093/sleep/34.5.601

42. Karaman S, Karaman T, Dogru S, et al. Prevalence of sleep disturbance in chronic pain. Eur Rev Med Pharmacol Sci. 2014;18(17):2475-2481.

43. Vinik A, Emir B, Cheung R, Whalen E. Relationship between pain relief and improvements in patient function quality of life in patients with painful diabetic peripheral neuropathy or postherpetic neuralgia treated with pregabalin. Clin Ther. 2013;35(5):612-623. doi:10.1016/j.clinthera.2013. 03.008

44. Jensen MP, Moore MR, Bockow TB, Ehde DM, Engel JM. Psychosocial factors and adjustment to chronic pain in persons with physical disabilities: a systematic review. Arch Phys Med Rehabil. 2011;92(1):146-160. doi:10.1016/j.apmr.2010 09.021

45. Gatchel RJ, Peng YB, Peters ML, Fuchs PN, Turk DC. The biopsychosocial approach to chronic pain: scientific advances and future directions. Psychol Bull. 2007;133(4):581-624. doi:10.1037/0033-2909.133.4.581

46. Turk DC, Fillingim RB, Ohrbach R, Patel KV. Assessment of psychosocial and functional impact of chronic pain. J Pain. 2016;17(9 Suppl):T21-T49. doi:10.1016/j.jpain.2016.02.006

47. Elfeky M, Yoneshiro T, Okamatsu-Ogura Y, Kimura K. Adiponectin suppression of late inflammatory mediator, HMGB1-induced cytokine expression in RAW264 macrophage cells. J Biochem. 2018;163(2):143-153. doi:10.1093/jb/mvx069

48. Park J, Newman D, Engstrom G, Hammar LM, Swall A. The moderating and covarying effects of social support and pain intensity on depressive symptomology among racially and ethnically diverse older adults. Pain Manag. 2017;7(1):19-32. doi:10.2217/pmt-2016-0027

49. Helmhout PH, Staal JB, Heymans MW, Harts CC, Hendriks EJ, de Bie RA. Prognostic factors for perceived recovery or functional improvement in non-specific low back pain: secondary analyses of three randomized clinical trials. Eur Spine J. 2010;19(4):650-659. doi:10.1007/s00586-009-1254-8

50. Leung YY, Teo SL, Chua MB, Raman P, Liu C, Chan A. Living arrangements, social networks and onset or progression of pain among older adults in Singapore. Geriatr Gerontol Int. 2016;16 (6):693-700. doi:10.1111/ggi.12539

51. Melloh M, Elfering A, Stanton TR, et al. Who is likely to develop persistent low back pain? A longitudinal analysis of prognostic occupational factors. Work. 2013;46(3):297-311. doi:10.3233/ WOR-131672

52. Melloh M, Elfering A, Chapple CM, et al. Prognostic occupational factors for persistent low back pain in primary care. Int Arch Occup Environ Health. 2013;86(3):261-269. doi:10. 1007/s00420-012-0761-9

53. McWilliams LA, Kowal J, Verrier MJ, Dick BD. Do pain-related support preferences moderate relationships between chronic pain patients' reports of support received and psychosocial functioning? Pain Med. 2017;18(12):2331-2339.
54. Abbasi M, Dehghani M, Keefe FJ, Jafari H, Behtash H, Shams J. Spouse-assisted training in pain coping skills and the outcome of multidisciplinary pain management for chronic low back pain treatment: a 1-year randomized controlled trial. Eur J Pain. 2012;16(7):1033-1043. doi:10.1002/j.1532-2149.2011.00097.x

55. Keefe FJ, Blumenthal J, Baucom D, et al. Effects of spouse-assisted coping skills training and exercise training in patients with osteoarthritic knee pain: a randomized controlled study. Pain. 2004;110(3):539-549. doi:10.1016/j.pain.2004.03. 022

56. Atkinson AJ, Colburn WA, DeGruttola VG, et al.; Biomarkers Definitions Working Group. Biomarkers and surrogate endpoints: preferred definitions and conceptual framework. Clin Pharmacol Ther. 2001;69(3):89-95. doi:10.1067/mcp.2001.113989

57. Gunn J, Hill MM, Cotten BM, Deer TR. An analysis of biomarkers in patients with chronic pain. Pain Physician. 2020;23(1): E41-E49. doi:10.36076/ppj.2020/23/E41

58. Marceau LD, Link C, Jamison RN, Carolan S. Electronic diaries as a tool to improve pain management: is there any evidence? Pain Med. 2007;8(Suppl 3):S101-109. doi:10.1111/j.1526-4637. 2007.00374.x

59. Melzack R. The short-form McGill Pain Questionnaire. Pain. 1987;30(2):191-197. doi:10.1016/0304-3959(87)91074-8

60. Jensen MP, Gammaitoni AR, Olaleye DO, Oleka N, Nalamachu SR, Galer BS. The pain quality assessment scale: assessment of pain quality in carpal tunnel syndrome. J Pain. 2006;7(11):823-832. doi:10.1016/j.jpain.2006.04.003

61. Freynhagen R, Baron R, Gockel U, Tölle TR. painDETECT: a new screening questionnaire to identify neuropathic components in patients with back pain. Curr Med Res Opin. 2006;22 (10):1911-1920. doi:10.1185/030079906X132488

62. Gammaitoni AR, Smugar SS, Jensen MP, et al. Predicting response to pregabalin from pretreatment pain quality: clinical applications of the pain quality assessment scale. Pain Med. 2013;14(4):526-532. doi:10.1111/j.1526-4637.2012.01423.x

63. Bouhassira D, Attal N, Fermanian J, et al. Development and validation of the Neuropathic Pain Symptom Inventory. Pain. 2004;108(3):248-257. doi:10.1016/j.pain.2003.12.024

64. Arendt-Nielsen L, Yarnitsky D. Experimental and clinical applications of quantitative sensory testing applied to skin, muscles and viscera. J Pain. 2009;10(6):556-572. doi:10.1016/j.jpain.20 09.02.002

65. Backonja MM, Attal N, Baron R, et al. Value of quantitative sensory testing in neurological and pain disorders: NeuPSIG consensus. Pain. 2013;154(9):1807-1819. doi:10.1016/j.pain.20 13.05 .047

66. Geber C, Klein T, Azad S, et al. Test-retest and interobserver reliability of quantitative sensory testing according to the protocol of the German Research Network on Neuropathic Pain (DFNS): a multi-centre study. Pain. 2011;152(3):548-556. doi:10.1016/j. pain.2010.11.013

67. Baron R, Maier C, Attal N, et al. Peripheral neuropathic pain: a mechanism-related organizing principle based on sensory profiles. Pain. 2017;158(2):261-272. doi:10.1097/j.pain.0000000000000753

68. Freeman R, Baron R, Bouhassira D, Cabrera J, Emir B. Sensory profiles of patients with neuropathic pain based on the neuropathic pain symptoms and signs. Pain. 2014;155(2):367-376. doi:10.1016/j.pain.2013.10.023

69. Baron R, Förster M, Binder A. Subgrouping of patients with neuropathic pain according to pain-related sensory abnormalities: a first step to a stratified treatment approach. Lancet Neurol. 2012;11(11):999-1005. doi:10.1016/S1474-4422(12)70189-8

70. Malmström EM, Stjerna J, Högestätt ED, Westergren $H$. Quantitative sensory testing of temperature thresholds: possible biomarkers for persistent pain? J Rehabil Med. 2016;48(1):43-47. doi:10.2340/16501977-2024 
71. Demant DT, Lund K, Vollert J, et al. The effect of oxcarbazepine in peripheral neuropathic pain depends on pain phenotype: a randomised, double-blind, placebo-controlled phenotype-stratified study. Pain. 2014;155(11):2263-2273. doi:10.1016/j.pain.2014.08.014

72. Ranoux D, Attal N, Morain F, Bouhassira D. Botulinum toxin type A induces direct analgesic effects in chronic neuropathic pain. Ann Neurol. 2008;64(3):274-283. doi:10.1002/ana.21427

73. Westermann A, Krumova EK, Pennekamp W, Horch C, Baron R, Maier C. Different underlying pain mechanisms despite identical pain characteristics: a case report of a patient with spinal cord injury. Pain. 2012;153(7):1537-1540. doi:10.1016/j.pain.2012.02. 031

74. Rolke R, Baron R, Maier C, et al. Quantitative sensory testing in the German Research Network on Neuropathic Pain (DFNS): standardized protocol and reference values. Pain. 2006;123 (3):231-243. doi:10.1016/j.pain.2006.01.041

75. Reimer M, Sachau J, Forstenpointner J, Baron R. Bedside testing for precision pain medicine. Curr Opin Support Palliat Care. 2021;15(2):116-124. doi:10.1097/SPC.0000000000000556

76. Reimer M, Forstenpointner J, Hartmann A, et al. Sensory bedside testing: a simple stratification approach for sensory phenotyping. Pain Rep. 2020;5(3):e820. doi:10.1097/PR9.0000000000000820

77. Zhu GC, Böttger K, Slater H, et al. Concurrent validity of a low-cost and time-efficient clinical sensory test battery to evaluate somatosensory dysfunction. Eur J Pain. 2019;23(10): 1826-1838. doi:10.1002/ejp.1456

78. Wasan AD, Alter BJ, Edwards RR, et al. Test-retest and inter-examiner reliability of a novel bedside quantitative sensory testing battery in postherpetic neuralgia patients. J Pain. 2020;21 (7-8):858-868. doi:10.1016/j.jpain.2019.11.013

79. Koulouris AE, Edwards RR, Dorado K, et al. Reliability and validity of the Boston Bedside Quantitative Sensory Testing Battery for Neuropathic Pain. Pain Med. 2020;21(10):23 36-2347. doi:10.1093/pm/pnaa192

80. Yarnitsky D. Conditioned pain modulation (the diffuse noxious inhibitory control-like effect): its relevance for acute and chronic pain states. Curr Opin Anaesthesiol. 2010;23(5):611-615. doi:10. 1097/ACO.0b013e32833c348b

81. Koroschetz J, Rehm SE, Gockel U, et al. Fibromyalgia and neuropathic pain-differences and similarities. A comparison of 3057 patients with diabetic painful neuropathy and fibromyalgia. BMC Neurol. 2011;11:55. doi:10.1186/1471-2377-11-55

82. Yarnitsky D, Granot M, Granovsky Y. Pain modulation profile and pain therapy: between pro- and antinociception. Pain. 2014;155(4):663-665. doi:10.1016/j.pain.2013.11.005

83. Sprenger C, Bingel U, Büchel C. Treating pain with pain: supraspinal mechanisms of endogenous analgesia elicited by heterotopic noxious conditioning stimulation. Pain. 2011;152 (2):428-439. doi:10.1016/j.pain.2010.11.018

84. Yarnitsky D, Granot M, Nahman-Averbuch H, Khamaisi M, Granovsky Y. Conditioned pain modulation predicts duloxetine efficacy in painful diabetic neuropathy. Pain. 2012;153 (6):1193-1198. doi:10.1016/j.pain.2012.02.021

85. Petersen KK, Arendt-Nielsen L, Simonsen O, Wilder-Smith O, Laursen MB. Presurgical assessment of temporal summation of pain predicts the development of chronic postoperative pain 12 months after total knee replacement. Pain. 2015;156(1):55-61. doi:10.1016/j.pain.0000000000000022

86. Martucci KT, Ng P, Mackey S. Neuroimaging chronic pain: what have we learned and where are we going? Future Neurol. 2014;9 (6):615-626. doi:10.2217/fnl.14.57

87. Vartiainen N, Kirveskari E, Kallio-Laine K, Kalso E, Forss N. Cortical reorganization in primary somatosensory cortex in patients with unilateral chronic pain. J Pain. 2009;10(8): 854-859. doi:10.1016/j.jpain.2009.02.006
88. Rosenberger $\mathrm{C}$, Thürling $\mathrm{M}$, Forsting $\mathrm{M}$, Elsenbruch $\mathrm{S}$, Timmann D, Gizewski ER. Contributions of the cerebellum to disturbed central processing of visceral stimuli in irritable bowel syndrome. Cerebellum. 2013;12(2):194-198. doi:10.1007/s123 11-012-0413-3

89. Moulton EA, Elman I, Pendse G, Schmahmann J, Becerra L, Borsook D. Aversion-related circuitry in the cerebellum: responses to noxious heat and unpleasant images. $J$ Neurosci. 2011;31(10):3795-3804. doi:10.1523/JNEUROSCI.6709-10.2011

90. Simons LE, Moulton EA, Linnman C, Carpino E, Becerra L, Borsook D. The human amygdala and pain: evidence from neuroimaging. Hum Brain Mapp. 2014;35(2):527-538. doi:10. 1002/hbm.22199

91. Aoki Y, Inokuchi R, Suwa H. Reduced N-acetylaspartate in the hippocampus in patients with fibromyalgia: a meta-analysis. Psychiatry Res. 2013;213(3):242-248. doi:10.1016/j.pscychresns.2013.03.008

92. Baliki MN, Geha PY, Fields HL, Apkarian AV. Predicting value of pain and analgesia: nucleus accumbens response to noxious stimuli changes in the presence of chronic pain. Neuron. 2010;66 (1):149-160. doi:10.1016/j.neuron.2010.03.002

93. Becerra L, Morris S, Bazes S, et al. Trigeminal neuropathic pain alters responses in CNS circuits to mechanical (brush) and thermal (cold and heat) stimuli. $J$ Neurosci. 2006;26(42): 10646-10657. doi:10.1523/JNEUROSCI.2305-06.2006

94. Latremoliere A, Woolf CJ. Central sensitization: a generator of pain hypersensitivity by central neural plasticity. J Pain. 2009;10 (9):895-926. doi:10.1016/j.jpain.2009.06.012

95. Woolf CJ. Central sensitization: implications for the diagnosis and treatment of pain. Pain. 2011;152(3 Suppl):S2-S15. doi:10. 1016/j.pain.2010.09.030

96. Harris RE. Acupuncture "rewires" the brain ... with lasting effects. J Altern Complement Med. 2017;23(6):405-406. doi:10. 1089/acm.2017.29027.reh

97. Duff EP, Vennart W, Wise RG, et al. Learning to identify CNS drug action and efficacy using multistudy fMRI data. Sci Transl Med. 2015;7(274):274ra216. doi:10.1126/scitranslmed.3008438

98. Cummiford CM, Nascimento TD, Foerster BR, et al. Changes in resting state functional connectivity after repetitive transcranial direct current stimulation applied to motor cortex in fibromyalgia patients. Arthritis Res Ther. 2016;18:40. doi:10.1186/s13075-016-0934-0

99. Harris RE, Napadow V, Huggins JP, et al. Pregabalin rectifies aberrant brain chemistry, connectivity, and functional response in chronic pain patients. Anesthesiology. 2013;119(6):1453-1464. doi:10.1097/ALN.0000000000000017

100. Reckziegel D, Bailey H, Cottam WJ, et al. Imaging pain relief in osteoarthritis (IPRO): protocol of a double-blind randomised controlled mechanistic study assessing pain relief and prediction of duloxetine treatment outcome. BMJ Open. 2017;7(6):e014013. doi:10.1136/bmjopen-2016-014013

101. Greenwald MK, Johanson CE, Moody DE, et al. Effects of buprenorphine maintenance dose on mu-opioid receptor availability, plasma concentrations, and antagonist blockade in heroin-dependent volunteers. Neuropsychopharmacology. 2003; 28(11):2000-2009. doi:10.1038/sj.npp.1300251

102. Upadhyay J, Anderson J, Baumgartner R, et al. Modulation of CNS pain circuitry by intravenous and sublingual doses of buprenorphine. Neuroimage. 2012;59(4):3762-3773. doi:10.10 16/j.neuroimage.2011.11.034

103. Wise RG, Rogers R, Painter D, et al. Combining fMRI with a pharmacokinetic model to determine which brain areas activated by painful stimulation are specifically modulated by remifentanil. Neuroimage. 2002;16(4):999-1014. doi:10.1006/nimg.2002.1146

104. Wilson SG, Smith SB, Chesler EJ, et al. The heritability of antinociception: common pharmacogenetic mediation of five neurochemically distinct analgesics. $J$ Pharmacol Exp Ther. 2003;304(2):547-559. doi:10.1124/jpet.102.041889 
105. Young EE, Lariviere WR, Belfer I. Genetic basis of pain variability: recent advances. $J$ Med Genet. 2012;49(1):1-9. doi:10. 1136/jmedgenet-2011-100386

106. Mogil JS, Wilson SG, Bon K, et al. Heritability of nociception I: responses of 11 inbred mouse strains on 12 measures of nociception. Pain. 1999;80(1-2):67-82. doi:10.1016/S03043959(98)00197-3

107. Mogil JS, Wilson SG, Bon K, et al. Heritability of nociception II. 'Types' of nociception revealed by genetic correlation analysis Pain. 1999;80(1-2):83-93. doi:10.1016/S0304-3959(98)00196-1

108. Lariviere WR, Wilson SG, Laughlin TM, et al. Heritability of nociception. III. Genetic relationships among commonly used assays of nociception and hypersensitivity. Pain. 2002;97(12):75-86. doi:10.1016/S0304-3959(01)00492-4

109. Weinshilboum RM, Wang L. Pharmacogenomics: precision medicine and drug response. Mayo Clin Proc. 2017;92(11):17 11-1722. doi:10.1016/j.mayocp.2017.09.001

110. Weinshilboum RM, Wang L. Pharmacogenetics and pharmacogenomics: development, science, and translation. Annu Rev Genomics Hum Genet. 2006;7:223-245. doi:10.1146/annurev. genom.6.080604.162315

111. Mogil JS. Pain genetics: past, present and future. Trends Genet. 2012;28(6):258-266. doi:10.1016/j.tig.2012.02.004

112. Muralidharan A, Smith MT. Pain, analgesia and genetics. J Pharm Pharmacol. 2011;63(11):1387-1400. doi:10.1111/j.20 42-7158.2011.01340.x

113. Klein TE, Altman RB, Eriksson N, et al. Estimation of the warfarin dose with clinical and pharmacogenetic data. $N$ Engl $J$ Med. 2009;360(8):753-764.

114. Wei MY, Ito MK, Cohen JD, Brinton EA, Jacobson TA. Predictors of statin adherence, switching, and discontinuation in the USAGE survey: understanding the use of statins in America and gaps in patient education. J Clin Lipidol. 2013;7(5):472-483. doi:10.1016/j.jacl.2013.03.001

115. Aletaha D. Precision medicine and management of rheumatoid arthritis. J Autoimmun. 2020;110:102405. doi:10.1016/j.jaut.20 20.102405

116. Piccart-Gebhart MJ, Procter M, Leyland-Jones B, et al. Trastuzumab after adjuvant chemotherapy in HER2-positive breast cancer. $N$ Engl J Med. 2005;353(16):1659-1672. doi:10. 1056/NEJMoa052306

117. La Du BN, Bartels CF, Nogueira CP, et al. Phenotypic and molecular biological analysis of human butyrylcholinesterase variants. Clin Biochem. 1990;23(5):423-431. doi:10.1016/00099120(90)90187-Y

118. Gonsalves SG, Dirksen RT, Sangkuhl K, et al. Clinical Pharmacogenetics Implementation Consortium (CPIC) guideline for the use of potent volatile anesthetic agents and succinylcholine in the context of RYR1 or CACNA1S genotypes. Clin Pharmacol Ther. 2019;105(6):1338-1344. doi:10.1002/ cpt.1319

119. Larach MG, Gronert GA, Allen GC, Brandom BW, Lehman EB. Clinical presentation, treatment, and complications of malignant hyperthermia in North America from 1987 to 2006. Anesth Analg. 2010;110(2):498-507. doi:10.1213/ANE.0b013e3181c6b9b2

120. Rosero EB, Adesanya AO, Timaran CH, Joshi GP. Trends and outcomes of malignant hyperthermia in the United States, 2000 to 2005. Anesthesiology. 2009;110(1):89-94. doi:10.1097/ALN.0b0 $13 \mathrm{e} 318190 \mathrm{bb} 08$

121. Agarwal D, Udoji MA, Trescot A. Genetic testing for opioid pain management: a primer. Pain Ther. 2017;6(1):93-105. doi:10. 1007/s40122-017-0069-2

122. Smith DM, Weitzel KW, Elsey AR, et al. CYP2D6-guided opioid therapy improves pain control in CYP2D6 intermediate and poor metabolizers: a pragmatic clinical trial. Genet Med. 2019;21 (8):1842-1850. doi:10.1038/s41436-018-0431-8
123. Ingelman-Sundberg M. Genetic polymorphisms of cytochrome P450 2D6 (CYP2D6): clinical consequences, evolutionary aspects and functional diversity. Pharmacogenomics J. 2005;5(1):6-13. doi:10.1038/sj.tpj.6500285

124. Webster LR, Belfer I. Pharmacogenetics and personalized medicine in pain management. Clin Lab Med. 2016;36(3):493-506. doi:10.1016/j.cll.2016.05.007

125. Hicks JK, Sangkuhl K, Swen JJ, et al. Clinical pharmacogenetics implementation consortium guideline (CPIC) for CYP2D6 and CYP2C19 genotypes and dosing of tricyclic antidepressants: 2016 update. Clin Pharmacol Ther. 2017;102(1):37-44. doi:10.1002/ cpt.597

126. Hicks JK, Swen JJ, Thorn CF, et al. Clinical Pharmacogenetics Implementation Consortium guideline for CYP2D6 and CYP2C19 genotypes and dosing of tricyclic antidepressants. Clin Pharmacol Ther. 2013;93(5):402-408. doi:10.1038/clpt.20 13.2

127. Dean L. Amitriptyline therapy and CYP2D6 and CYP2C19 genotype. In: Pratt VM, Scott SA, Pirmohamed M, editors. Medical Genetics Summaries. Bethesda (MD): National Center for Biotechnology Information (US); 2012.

128. Theken KN, Lee CR, Gong L, et al. Clinical Pharmacogenetics Implementation Consortium guideline (CPIC) for CYP2C9 and nonsteroidal anti-inflammatory drugs. Clin Pharmacol Ther. 2020;108(2):191-200. doi:10.1002/cpt.1830

129. Grosser T, Smyth E, FitzGerald G. Pharmocotherapy of inflammation, fever, pain, and gout. In: Brunton LL, Hilal-Dandan R, Knollmann BC, editors. Goodman \& Gilman's: The Pharmacological Basis of Therapeutics. 13th ed. New York, NY: McGraw-Hill; 2018:685-710.

130. Wongrakpanich S, Wongrakpanich A, Melhado K, Rangaswami J. A comprehensive review of non-steroidal anti-inflammatory drug use in the elderly. Aging Dis. 2018;9(1):143-150. doi:10.14336/ AD.2017.0306

131. Ong CK, Lirk P, Tan CH, Seymour RA. An evidence-based update on nonsteroidal anti-inflammatory drugs. Clin Med Res. 2007;5(1):19-34. doi:10.3121/cmr.2007.698

132. Davis A, Robson J. The dangers of NSAIDs: look both ways. Br J Gen Pract. 2016;66(645):172-173. doi:10.3399/bjgp16X684433

133. Zorina-Lichtenwalter K, Meloto CB, Khoury S, Diatchenko L. Genetic predictors of human chronic pain conditions. Neuroscience. 2016;338:36-62.

134. Andersen S, Skorpen F. Variation in the COMT gene: implications for pain perception and pain treatment. Pharmacogenomics. 2009;10(4):669-684. doi:10.2217/pgs.09.13

135. Männistö PT, Kaakkola S. Catechol-O-methyltransferase (COMT): biochemistry, molecular biology, pharmacology, and clinical efficacy of the new selective COMT inhibitors. Pharmacol Rev. 1999;51(4):593-628.

136. Sadhasivam S, Chidambaran V, Olbrecht VA, et al. Genetics of pain perception, COMT and postoperative pain management in children. Pharmacogenomics. 2014;15(3):277-284. doi:10.2217/ pgs. 13.248

137. Tanaka BS, Zhao P, Dib-Hajj FB, et al. A gain-of-function mutation in Nav1.6 in a case of trigeminal neuralgia. Mol Med. 2016;22:338-348. doi:10.2119/molmed.2016.00131

138. Drenth JP, Waxman SG. Mutations in sodium-channel gene SCN9A cause a spectrum of human genetic pain disorders. J Clin Invest. 2007;117(12):3603-3609. doi:10.117 2/JCI33297

139. Cox JJ, Reimann F, Nicholas AK, et al. An SCN9A channelopathy causes congenital inability to experience pain. Nature. 2006;444(7121):894-898. doi:10.1038/nature05413

140. Reimann F, Cox JJ, Belfer I, et al. Pain perception is altered by a nucleotide polymorphism in SCN9A. Proc Natl Acad Sci U S A. 2010;107(11):5148-5153. doi:10.1073/pnas.0913181107 
141. Duan G, Guo S, Zhang Y, et al. The effect of SCN9A variation on basal pain sensitivity in the general population: an experimental study in young women. $J$ Pain. 2015;16(10):971-980. doi:10.1016/j.jpain.2015.06.011

142. Doppler K, Sommer C. [Neuropathic pain associated with Nav1.7 mutations: clinical picture and treatment]. Nervenarzt. 2013;84 (12):1428-1435. German. doi:10.1007/s00115-012-3621-7

143. Duan G, Han C, Wang Q, et al. A SCN10A SNP biases human pain sensitivity. Mol Pain. 2016;12:174480691666608. doi:10. 1177/1744806916666083

144. Bagal SK, Chapman ML, Marron BE, Prime R, Storer RI, Swain NA. Recent progress in sodium channel modulators for pain. Bioorg Med Chem Lett. 2014;24(16):3690-3699. doi:10. 1016/j.bmcl.2014.06.038

145. McCormack K, Santos S, Chapman ML, et al. Voltage sensor interaction site for selective small molecule inhibitors of voltage-gated sodium channels. Proc Natl Acad Sci U S A. 2013;110(29):E2724-2732. doi:10.1073/pnas.1220844110

146. Ahuja S, Mukund S, Deng L, et al. Structural basis of Nav1.7 inhibition by an isoform-selective small-molecule antagonist. Science. 2015;350(6267):aac5464. doi:10.1126/science.aac5464

147. Alexandrou AJ, Brown AR, Chapman ML, et al. Subtypeselective small molecule inhibitors reveal a fundamental role for Nav1.7 in nociceptor electrogenesis, axonal conduction and presynaptic release. PLoS One. 2016;11(4):e0152405. doi:10.1371/ journal.pone.0152405

148. Jaenisch R, Bird A. Epigenetic regulation of gene expression: how the genome integrates intrinsic and environmental signals. Nat Genet. 2003;33:245-254. doi:10.1038/ng1089

149. Orphanides G, Reinberg D. A unified theory of gene expression. Cell. 2002;108(4):439-451. doi:10.1016/S0092-8674(02)00655-4

150. Bird A. Perceptions of epigenetics. Nature. 2007;447(71 43):396-398. doi:10.1038/nature05913

151. Lessans S, Dorsey SG. The role for epigenetic modifications in pain and analgesia response. Nurs Res Pract. 2013;2013:961493.

152. Descalzi G, Ikegami D, Ushijima T, Nestler EJ, Zachariou V, Narita M. Epigenetic mechanisms of chronic pain. Trends Neurosci. 2015;38(4):237-246. doi:10.1016/j.tins.2015.02.001

153. Cherng $\mathrm{CH}$, Lee $\mathrm{KC}$, Chien $\mathrm{CC}$, et al. Baicalin ameliorates neuropathic pain by suppressing HDAC1 expression in the spinal cord of spinal nerve ligation rats. J Formos Med Assoc. 2014;113 (8):513-520. doi:10.1016/j.jfma.2013.04.007

154. Winkler I, Blotnik S, Shimshoni J, Yagen B, Devor M, Bialer M. Efficacy of antiepileptic isomers of valproic acid and valpromide in a rat model of neuropathic pain. Br J Pharmacol. 2005;146 (2):198-208. doi:10.1038/sj.bjp.0706310

155. Bai G, Wei D, Zou S, Ren K, Dubner R. Inhibition of class II histone deacetylases in the spinal cord attenuates inflammatory hyperalgesia. Mol Pain. 2010;6:51. doi:10.1186/1744-8069-6-51

156. Uchida H, Ma L, Ueda H. Epigenetic gene silencing underlies C-fiber dysfunctions in neuropathic pain. $J$ Neurosci. 2010;30 (13):4806-4814. doi:10.1523/JNEUROSCI.5541-09.2010

157. Pickering V, Jay Gupta R, Quang P, Jordan RC, Schmidt BL. Effect of peripheral endothelin-1 concentration on carcinoma-induced pain in mice. Eur J Pain. 2008;12 (3):293-300. doi:10.1016/j.ejpain.2007.06.001

158. Turner JD, Pelascini LP, Macedo JA, Muller CP. Highly individual methylation patterns of alternative glucocorticoid receptor promoters suggest individualized epigenetic regulatory mechanisms. Nucleic Acids Res. 2008;36(22):7207-7218. doi:10. 1093/nar/gkn897
159. Chen P, Jiang T, Ouyang J, Cui Y, Chen Y. Epigenetic programming of diverse glucocorticoid response and inflammatory/immune-mediated disease. Med Hypotheses. 2009;73(5):657-658. doi:10.1016/j.mehy.2009.08.013

160. Pharo GH, Zhou L. Pharmacologic management of cancer pain. $J$ Am Osteopath Assoc. 2005;105(11 Suppl 5):S21-28.

161. World Health Organization. WHO's Cancer Pain Ladder for Adults. World Health Organization; 2010.

162. Klepstad P, Rakvåg TT, Kaasa S, et al. The 118 A > $\mathrm{G}$ polymorphism in the human mu-opioid receptor gene may increase morphine requirements in patients with pain caused by malignant disease. Acta Anaesthesiol Scand. 2004;48 (10):1232-1239. doi:10.1111/j.1399-6576.2004.00517.x

163. Andreassen TN, Eftedal I, Klepstad P, et al. Do CYP2D6 genotypes reflect oxycodone requirements for cancer patients treated for cancer pain? A cross-sectional multicentre study. Eur J Clin Pharmacol. 2012;68(1):55-64. doi:10.1007/s00228-011-1093-5

164. Jacox AK, Carr DB, Payne R. Management of Cancer Pain. Clinical Practice Guideline No. 9 (AHCPR Publication No. 94-0592). Rockville, Md: Agency for Health Care Policy and Research; 1994.

165. Shuman AG, Terrell JE, Light E, et al. Predictors of pain among patients with head and neck cancer. Arch Otolaryngol Head Neck Surg. 2012;138(12):1147-1154. doi:10.1001/jamaoto.2013.853

166. Galloway SK, Baker M, Giglio P, et al. Depression and anxiety symptoms relate to distinct components of pain experience among patients with breast cancer. Pain Res Treat. 2012;2012:851276.

167. Azizoddin DR, Schreiber K, Beck MR, et al. Chronic pain severity, impact, and opioid use among patients with cancer: an analysis of biopsychosocial factors using the CHOIR learning health care system. Cancer. 2021;127:3254-3263. doi:10.1002/cncr.33645

168. Glare P, Costa D, Nicholas M. Psychosocial characteristics of cancer-related pain in patients attending specialist pain clinics in Australia and New Zealand. Psychooncology. 2020;29 (12):2097-2100. doi:10.1002/pon.5474

169. Johannsen M, Frederiksen Y, Jensen AB, Zachariae R. Psychosocial predictors of posttreatment pain after nonmetastatic breast cancer treatment: a systematic review and meta-analysis of prospective studies. J Pain Res. 2018;11:23-36. doi:10.2147/JPR.S124665

170. Morrison EJ, Flynn JM, Jones J, Byrd JC, Andersen BL. Individual differences in physical symptom burden and psychological responses in individuals with chronic lymphocytic leukemia. Ann Hematol. 2016;95(12):1989-1997. doi:10.1007/s00277-016-2790-z

171. Badr H, Milbury K. Associations between depression, pain behaviors, and partner responses to pain in metastatic breast cancer. Pain. 2011;152(11):2596-2604. doi:10.1016/j.pain.2011.08.002

172. Badr H, Shen MJ. Pain catastrophizing, pain intensity, and dyadic adjustment influence patient and partner depression in metastatic breast cancer. Clin J Pain. 2014;30(11):923-933. doi:10.1097/ AJP.0000000000000058

173. Leach CR, Troeschel AN, Wiatrek D, et al. Preparedness and cancer-related symptom management among cancer survivors in the first year post-treatment. Ann Behav Med. 2017;51 (4):587-598. doi:10.1007/s12160-017-9880-6

174. Schreiber KL, Martel MO, Shnol H, et al. Persistent pain in postmastectomy patients: comparison of psychophysical, medical, surgical, and psychosocial characteristics between patients with and without pain. Pain. 2013;154(5):660-668. doi:10.1016/j.pain.2012.11.015

175. Dubois MY, Follett KA. Pain medicine: the case for an independent medical specialty and training programs. Acad Med. 2014;89 (6):863-868. doi:10.1097/ACM.0000000000000265 


\section{Publish your work in this journal}

The Journal of Pain Research is an international, peer reviewed, open access, online journal that welcomes laboratory and clinical findings in the fields of pain research and the prevention and management of pain. Original research, reviews, symposium reports, hypothesis formation and commentaries are all considered for publication. The manuscript management system is completely online and includes a very quick and fair peer-review system, which is all easy to use. Visit http:// www.dovepress.com/testimonials.php to read real quotes from published authors. 